\title{
Video-assisted thoracoscopic surgery as a first-line treatment for mediastinal parathyroid adenomas: strategic value of imaging
}

\author{
L Amar, L Guignat, F Tissier ${ }^{1}$, B Richard ${ }^{2}$, O Vignaux ${ }^{3}$, Y Fulla ${ }^{2}$, P Legmann ${ }^{3}$, X Bertagna and P Bonnichon ${ }^{4}$ \\ Departments of Endocrinology, ${ }^{1}$ Pathology, ${ }^{2}$ Nuclear Medicine, ${ }^{3}$ Radiology and ${ }^{4}$ Surgery, Cochin Hospital, Paris, France \\ (Correspondence should be addressed to L Guignat, Department of Endocrinology, Cochin Hospital, 27 rue du Faubourg Saint-Jacques, 75014 Paris, \\ France; Email: laurence.guignat@cch.ap-hop-paris.fr)
}

\begin{abstract}
Objective: To present first-line thoracic surgery made possible by localization studies in three patients with ectopic parathyroid adenomas.

Design and methods: Three patients with ectopic parathyroid tissue in the mediastinum were examined by ultrasound, technetium-99m sestamibi scintigraphy, computed tomography (CT), and venous catheterization with measurement of parathyroid hormone. Without previous cervical exploration, video-assisted thoracic surgery (VATS) was used in all cases to avoid the need for thoracic open surgical procedures.

Results and conclusions: The mediastinal parathyroid glands were all detected at scintigraphy, and CT and venous catheterization were helpful in anatomic and functioning characterization. All pathologic glands were successfully resected, with only one minor complication. VATS can safely remove a deep mediastinal parathyroid adenoma and avoid more aggressive open approaches. In an experienced referral center, systematic and sophisticated imaging studies may accurately identify and localize rare ectopic parathyroid adenomas, and avoid cervical surgery.
\end{abstract}

European Journal of Endocrinology 150 141-147

\section{Introduction}

Primary hyperparathyroidism has become a frequent disease, most often detected on routine calcium screening in asymptomatic subjects $(1-5)$. Most patients have a sporadic and solitary cervical adenoma. The operative approach was established by the 1990 consensus panel (3), and approved by a recent workshop (5): a bilateral neck exploration is performed under general anesthesia, with a thorough search for all parathyroid tissue $(6-8)$. The use of non-invasive localization procedures is agreed after cervical surgery has failed, because the presence of an ectopic gland is more likely and because it seems to reduce the complication rate of subsequent surgery $(3,5,9-12)$.

This classical strategy has recently been modified by many surgeons by the use of an accurate imaging procedure. The convergent localization of a single cervical parathyroid adenoma with both ultrasonography and technetium-99m sestamibi (Tc99m-sestamibi) scintigraphy allows minimally invasive parathyroidectomy by unilateral neck exploration under local anesthesia, endoscopic parathyroidectomy or radio-guided surgery, with a success rate of $90-95 \%$ and less than $5 \%$ morbidity (13-24). This approach might facilitate the decision to operate on asymptomatic patients as often occurs in perimenopausal women, vertebral osteopenia, and vitamin D deficiency, as well as in subjects who are elderly and have poor health status $(4,8$, 13-15, 25-30).

Another major interest of systematic preoperative imaging is the discovery of ectopic adenomas requiring a trans-sternal or transthoracic approach, which are present in $1.25-2 \%$ of patients $(31-36)$. In such cases, an optimal strategy would be to perform a firstline thoracoscopic approach.

We report here our experience in three cases of ectopic parathyroid glands successfully resected by videoassisted thoracic surgery (VATS) performed as a firstline treatment.

\section{Methods}

Preoperative cervical ultrasound and Tc99m-sestamibi scintigraphy for primary hyperparathyroidism have been performed in all patients in our Department since 1993, always by the same operator (B R). After placing the patient in the supine position with the neck slightly extended, a complete sonographic survey 
is begun just above the suprasternal notch and continued superiorly to the upper border of the larynx, with a linear $7.5 \mathrm{MHz}$ transducer operating in black and with imaging and color doppler. A parathyroid adenoma appears as an oval hypoechogenic mass, sometimes containing cystic components, it is located adjacent to the thyroid gland, and it is mobile during swallowing. Obviously, deep mediastinal parathyroid lesions are inaccessible by ultrasound.

Double-phase Tc99m-sestamibi (technetium-hexasis, 2-methoxy-isobutyl-isonitrile; Cardiolite) scintigraphy (37-39) was also routinely performed. Neck and mediastinum images were acquired with a low-energy, high-resolution collimator, 5-15 min and $90 \mathrm{~min}$ after $550-740 \mathrm{MBq}$ Tc99m-sestamibi were intravenously injected. Images are recorded into a $256 \times 256$ matrix. A parathyroid adenoma appears as an area of increased activity seen on initial image and persisting on delayed images, in contrast to thyroid tissue in which the tracer is more quickly washed out. In each case of suspected ectopic mediastinal adenoma, anteroposterior planar and frontal, coronal, sagittal singlephoton emission computerized tomography (SPECT) images are also performed for better anatomic localization. Images are acquired in a matrix size of $128 \times 128$, a $^{\circ}$ angle step, and a time of $20 \mathrm{~s}$ per frame. Computed tomography (CT) scan sections were obtained at $5 \mathrm{~mm}$ intervals from the level of the angle of the mandible to the aortic arch before and after the intravenous administration of contrast agent. A parathyroid adenoma usually appears as a rounded, well-defined, homogeneous hypodense mass, raised in an intense way after injection at arterial time, but shorter compared to the vessels or the thyroid.

Because thoracic ectopic adenoma was suspected after the above imaging studies, venous catheterization of large veins in the neck and the mediastinum for the determination of parathyroid hormone (PTH) was performed as described previously (11), with a significant gradient when the local PTH level was at least twice the peripheral PTH value.

VATS was performed under general anesthesia using a double-lumen endotracheal tube by a single surgeon (P B). The patients were ventilated only via the opposite lung and were kept in a full lateral position. Three trocars were placed from the side of the chest of the adenoma through the third to fifth intercostal space, starting from the medial axillar to the anterior axillar and the medioclavicular line. A standard $10 \mathrm{~mm}$ rigid thoracoscope with a $0^{\circ}$ angle was used, normally viewing from the anterior axillar incision.

Intraoperative PTH levels were monitored with a rapid PTH assay, as described previously $(14,15)$.

\section{Results}

\section{Patient no. 1}

A primary hyperparathyroidism was diagnosed during a routine laboratory screening in a 36-year-old woman admitted for phlebitis (eventually correlated to a factor II deficit). Table 1 summarizes the biological data. She had silent renal stones. The absence of a familial history and the lack of association with other endocrine diseases such as pancreatic islet-cell, anterior pituitary and adrenal cortex lesions almost eliminated the diagnosis of multiple endocrine neoplasia (MEN)-1. No parathyroid tumor was identified with cervical ultrasound. The Tc99m-sestamibi parathyroid scintigraphy and SPECT demonstrated a focal area of increased uptake involving the right inferior side of the anterior mediastinum, which suggested an ectopic mediastinal parathyroid adenoma (Figs 1 and 2). CT showed a $1 \mathrm{~cm}$ mass located in front of the ascending aorta and superior vena cava (Fig. 3). The venous catheterization with measurement of the PTH level revealed a gradient with a step-up value crossing the right brachiocephalic vein and the superior vena cava. The diagnosis of a solitary mediastinal adenoma located in the inferior part of anterior mediastinum was made and VATS was performed. No abnormal tissue could be visualized in the anterior mediastinum during surgery. The surgeon, guided by the preoperative localization, made a large surgical resection of perivisceral fat tissue, including the thymus and mediastinal pleura covering the superior vena cava, aortic arch, and right atrium. A drop (from 146 to $4 \mathrm{ng} / \mathrm{l})$ in PTH levels occurred during the surgery, suggesting the removal of all hyperfunctioning tissue. The final pathology confirmed a $1 \mathrm{~cm}$ parathyroid tumor. The patient's serum ionized calcium has been normalized since the surgery at follow-up at 12 months, without any complications.

\section{Patient no. 2}

The survey of a 57-year-old woman with a history of breast cancer diagnosed 2 years earlier and considered

Table 1 Patient characteristics before operation.

\begin{tabular}{lccc}
\hline Patient no. & $\begin{array}{c}\text { Total serum calcium (mmol/l) } \\
\text { (high normal 2.6) }\end{array}$ & $\begin{array}{c}\text { Ionized serum calcium (mmol/l) } \\
\text { (high normal 1.29) }\end{array}$ & $\begin{array}{c}\text { Urine calcium } \\
(\mathrm{mmol} / 24 \mathrm{~h})\end{array}$ \\
\hline 1 & 2.59 & 1.51 & 6.0 \\
2 & 2.61 & 1.39 & 8.6 \\
3 & 2.89 & 1.49 & 158 \\
\hline
\end{tabular}




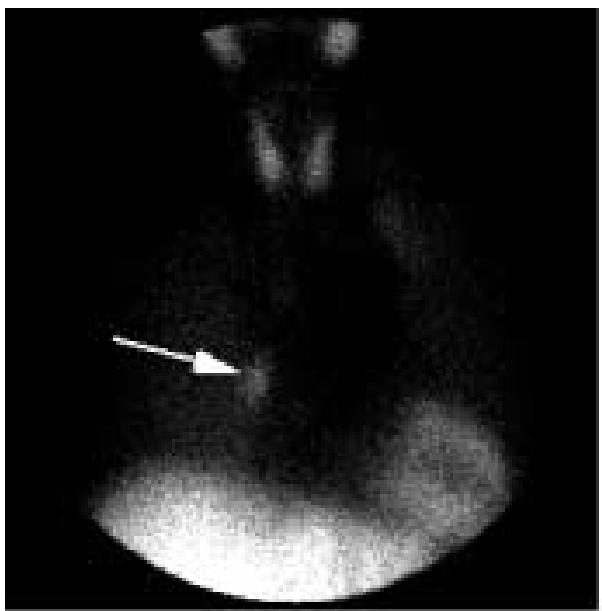

(a)

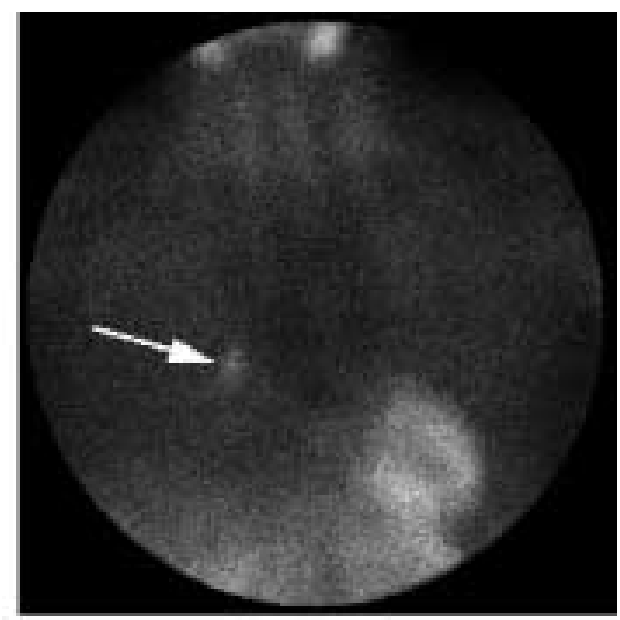

(b)

Figure 1 Sestamibi images at (a) $5 \mathrm{~min}$ and (b) 90 min demonstrating a mediastinal parathyroid adenoma in patient no. 1.

to be cured showed a primary hyperparathyroidism (Table 1). There was no indication of genetic disease. The cervical ultrasound detected no parathyroid mass. The Tc99m-sestamibi parathyroid scintigraphy demonstrated a focal area of increased uptake involving the right anterior mediastinum that suggested an ectopic parathyroid adenoma. The CT visualized two masses, one anterior mass looking like a hamartochondroma and an ovoid mass of $2 \mathrm{~cm}$ in front of the superior vena cava and ascending aorta corresponding to the image seen by scintigraphy and to the increases in the PTH level shown by venous catheterization. Using VATS, dissection of the adipose tissue in the upper anterior mediastinum was carried out and the
PTH level decreased intraoperatively (from 777 to $41 \mathrm{ng} / \mathrm{l})$. No postoperative complication occurred. A hypercellular parathyroid gland was found inside the fat tissue. Since there was no normal parathyroid tissue around, we cannot give a precise diagnosis between adenoma and hyperplasia. Serum ionized calcium has been normalized since surgery at followup at 31 months.

\section{Patient no. 3}

Primary hyperparathyroidism was diagnosed in an 82-year-old woman followed for wrist pain (Table 1). Her past medical history revealed no endocrine disease
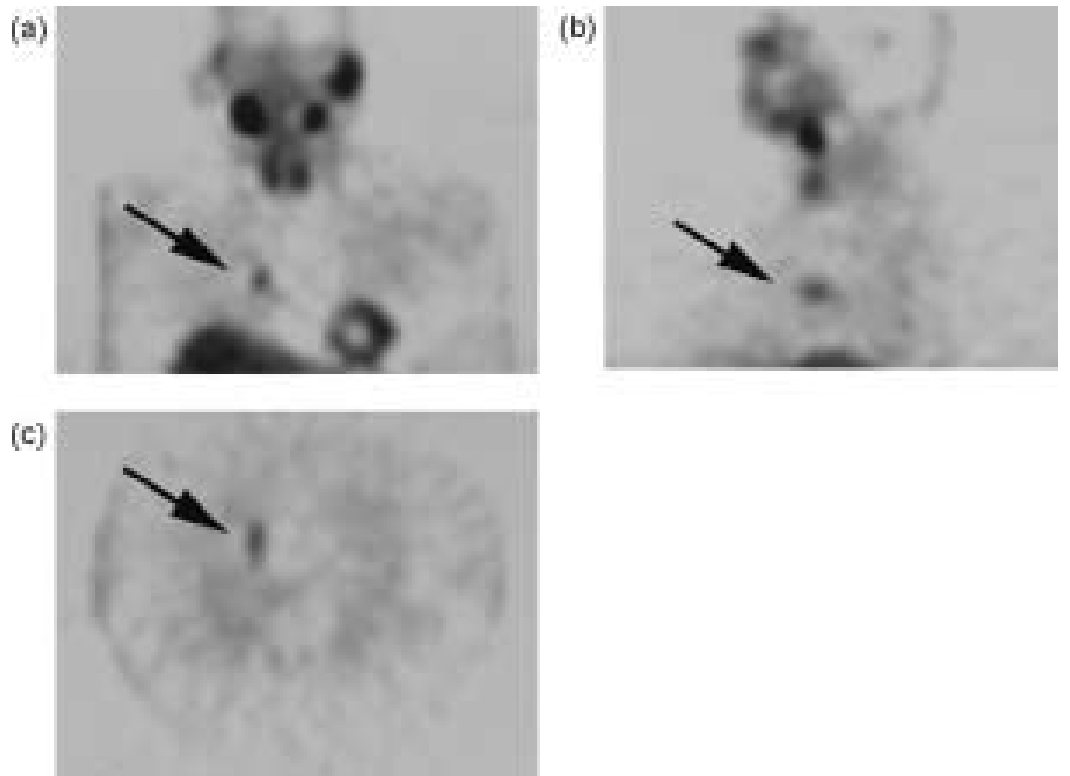

Figure 2 (a) Frontal, (b) coronal, and (c) axial sestamibi SPECT images demonstrating the parathyroid adenoma in the inferior part of the anterior mediastinum in patient no. 1. 


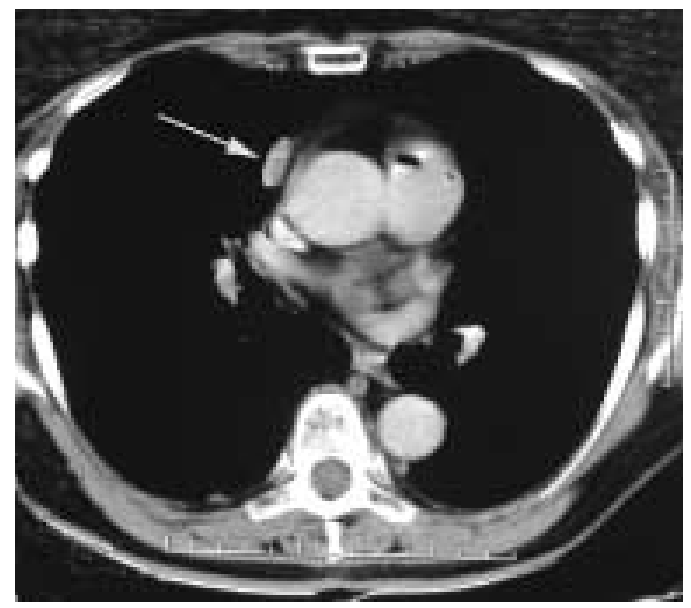

Figure 3 CT scan showing a parathyroid adenoma (arrow) in front of the ascending aorta in patient no. 1 .

but an atrial fibrillation for years. The cervical ultrasound was negative. The Tc99m-sestamibi scintigraphy revealed two locations of increased uptake: one dubious with regard to the left lobe of the thyroid and one in the upper left mediastinum. CT visualized one mass located near the thyroid which did not take the contrast as much as the rest of the thyroid, suggesting a thyroid adenoma, and a $1 \mathrm{~cm}$ node located above the aortic arch. The catheterization confirmed this diagnosis with an increase in the PTH level in the superior vena cava. Using VATS, the surgeon removed the adipose tissue in front of the aorta, which contained a $1 \mathrm{~cm}$ adenoma. The patient normalized her ionized calcium level, but developed transient hoarseness presumed to be due to damage to the left recurrent laryngeal nerve, which loops around the aortic arch.

\section{Discussion}

The possible sites of ectopic parathyroid tissue are parapharyngeal at the level of the mandible, intrathyroidal, and mediastinal. Most ectopic parathyroid adenomas are found in close approximation to the thymus gland $(9,31,32,36,40-43)$ and can be excised using a collar incision. Parathyroid adenomas deeper in the chest require a sternotomy or lateral thoracotomy $(32,41,42,44-48)$, angiographic ablation $(49,50)$, video-assisted mediastinal or thoracoscopic surgery (VAMS/VATS), or even an infrasternal approach in patients with pleural adhesions or pulmonary insufficiency $(51,52)$. VATS, developed by Landreneau et al. (53), is safe, offers the advantages of minimal invasive surgery, and does not interfere with other surgical approaches, with lower risks of re-operation. There are several reports in the literature of successful resections of ectopic parathyroid tissue using VATS, with rare complications (12, 34-36, $43,48,54-62$ ).
Preoperative localization tests being seldom used when a standard surgical approach is used, only a few patients have undergone first-line resection of mediastinal adenoma. Less than ten patients have been reported until now $(36,47,48,54,56-59,61$, 62). Cupisti et al. (36) recommended VATS as the first procedure only if the adenoma is clearly located in the chest deeper than the brachiocephalic vein. Furthermore, scintigraphic images were rarely further investigated to exclude non-specific fixation, by arteriography, selective venous catheterization, intraoperative PTH assay or radioguided dissection $(36,47,60,62)$. More often, only the CT scan was performed because the size of the solid structure was more than $15 \mathrm{~mm}$.

In our center, once the diagnosis of hyperparathyroidism has been confirmed, cervical ultrasonography and planar sestamibi scintigraphy are systematically performed. If both examinations are concurrent for a single cervical adenoma, unilateral neck exploration under local anesthesia is proposed, except in cases of suspected multiple abnormal parathyroid glands, familial hyperparathyroidism and/or MEN, coexistence of a thyroid disease requiring surgery, history of childhood irradiation to the neck and the head, allergy to local anesthetic drugs, severe psychiatric illness, and deafness. If, after the removal of the adenoma, the intraoperative PTH level falls by more than $50 \%$ with a final value that is within the normal range, the operation is terminated. If the intraoperative PTH does not fall and the patient has an indication for surgery as defined by the recent consensus, the operation is extended to seek all parathyroid glands. If ultrasonography is negative and planar scintigraphy shows mediastinal fixation, anatomic and functional characterization are further performed with SPECT, CT scan, venous catheterization, and intraoperative PTH assays. Indeed, a mediastinal focal area of uptake at scintigraphy without cervical fixation or ultrasound image may be a false positive of scintigraphy and a false negative of ultrasonography. In experienced hands, the main false negatives of cervical ultrasonography are explained by the small size of the parathyroid adenomas, misinterpretation of an intrathyroid image, retroesophageal, retropharyngotracheal or mediastinal localization, coexisting multinodular goiter, or postoperative changes. False positives of Tc99m-sestamibi scintigraphy at the mediastinal level are mainly tumoral (metastatic thyroid cancer, lung cancer, bone or lymph node metastases, thymoma) or inflammatory lesions (28, 63). For the second patient, even if the breast cancer was considered in remission, a metastatic node in the inferior mammary chain could not be ruled out. In addition, the superior portion of the right atrium and basal superoanterior right ventricular myocardium often appear as discrete isolated foci on Tc99m-sestamibi scintigraphy because they are considerably thicker than other parts of the right atrial and right ventricular muscle respectively, and because they are seen partly 
end-on in the anterior projection (64). Another potential pitfall is due to central venous pacemaker wires (65). False negative studies are more common in patients with small hyperplastic parathyroid glands and multiglandular disease $(39,64)$.

CT demonstrated tissue lesions with the features of parathyroid tissue (but not of lymph node in the second case) corresponding to scintigraphic uptake, and defined the precise anatomic localization. Positive venous catheterization, with a technique having low morbidity and high sensitivity $(11,66)$, was consistent with parathyroid tissue. CT and catheterization allowed us to exclude false-positive scintigraphy. A combination of scintigraphy and CT being concurrent, however, the use of catheterization might be discussed. Recent studies indicate that simultaneous acquisition of SPECT and CT images using the same imaging device provides a better anatomic localization $(67,68)$.

In our cases, the diagnosis of mediastinal parathyroid adenoma was made on the grounds of consistent imaging data. The patients had indications for surgery: the first one was young and had urinary stones; the second one had osteoporosis; the last one had calcemia $0.25 \mathrm{mmol} / \mathrm{l}$ above the normal reference range and osteoporosis. Definitive surgical approach by first-line thoracoscopy was planned. A dramatic decrease of intraoperative PTH values predicted a successful outcome, avoiding the need to extend resection because of the surgeon's inability to accurately visualize parathyroid glands in the mediastinal tissue and without localization of all glands in the neck.

Routine preoperative imaging with neck ultrasonography and scintigraphy allows the avoidance of exploration of the neck in cases of an ectopic parathyroid adenoma. In the case of negative neck ultrasonography combined with an ectopic image at scintigraphy, a CT scan should be performed in order to localize the image with more precision. Concurrent studies permit the removal of the mediastinal parathyroid tumor by first-line thoracic surgery, confirmed by the intraoperative measurement of PTH. Furthermore, a study made in the USA (69) demonstrated that routine preoperative localization with Tc99m-sestamibi and ultrasound scans is not more expensive than the cumulative costs of failure to identify the ectopic parathyroid adenoma when exploration without preoperative localization is performed. Our results stress the usefulness of this strategy.

\section{References}

1 Heath H III, Hodgson SF \& Kennedy MA. Primary hyperparathyroidism. Incidence, morbidity, and potential economic impact in a community. New England Journal of Medicine 1980302 189-193.

2 Scholz DA \& Purnell DC. Asymptomatic primary hyperparathyroidism. 10-year prospective study. Mayo Clinic Proceedings 1981 56 473-478.

3 Consensus Development Conference Panel. Diagnosis and management of asymptomatic primary hyperparathyroidism: Consensus
Development Conference statement. Annals of Internal Medicine $1991114593-597$.

4 Silverberg SJ, Shane E, Jacobs TP, Siris E \& Bilezikian JP. A 10-year prospective study of primary hyperparathyroidism with or without parathyroid surgery. New England Journal of Medicine 1999 341 1249-1255.

5 Bilezikian JP, Potts JT Jr, Fuleihan Gel-H, Kleerekoper M, Neer R, Peacock M et al. Summary statement from a workshop on asymptomatic primary hyperparathyroidism: a perspective for the 21st century. Journal of Bone and Mineral Research 200217 N2-N17.

6 Van Heerden JA \& Grant CS. Surgical treatment of primary hyperparathyroidism: an institutional prospective. World Journal of Surgery $199115688-692$.

7 Kaplan EL, Yashiro T \& Salti G. Primary hyperparathyroidism in the 1990s. Choice of surgical procedures for this disease. Annals of Surgery $1992 \mathbf{2 1 5}$ 300-317.

8 Sosa JA, Powe NR, Levine MA, Udelsman R \& Zeiger MA. Thresholds for surgery and surgical outcomes for patients with primary hyperparathyroidism: a national survey of endocrine surgeons. Journal of Clinical Endocrinology and Metabolism 1998 $832658-2665$.

9 Edis AJ, Sheedy PF, Beahrs OH \& Van Heerdan JA. Results of reoperation for hyperparathyroidism with evaluation of preoperative localization studies. Surgery $1978 \mathbf{8 4} 384-393$.

10 Miller DL. Pre-operative localization and interventional treatment of parathyroid tumors: when and how? World Journal of Surgery $199115706-715$.

11 Fayet P, Hoeffel C, Fulla Y, Legmann P, Hazebroucq V, Luton JP et al. Technetium-99m sestamibi scintigraphy, magnetic resonance imaging and venous blood sampling in persistent and recurrent hyperparathyroidism. British Journal of Radiology $1997 \mathbf{7 0}$ 459-464.

12 Feingold DL, Alexander HR, Chen CC, Libutti SK, Shawker TH, Simonds WF et al. Ultrasound and sestamibi scan as the only preoperative imaging tests in reoperation for parathyroid adenomas. Surgery 2000128 1103-1109.

13 Chapuis Y, Richard B, Fulla Y, Bonnichon P, Tarla E \& Icard P. Surgery of primary hyperparathyroidism by unilateral approach under local anesthesia and intraoperative determination of PTH 1-84. Annales d' Endocrinologie $199455171-174$.

14 Chapuis Y, Fulla Y, Bonnichon P, Tarla E, Abboud B, Pitre J et al. Values of ultrasonography, sestamibi scintigraphy, and intraoperative measurement of 1-84 PTH for unilateral neck exploration of primary hyperparathyroidism. World Journal of Surgery $199620835-840$.

15 Inabnet WB, Fulla Y, Richard B, Bonnichon P, Icard P \& Chapuis Y. Unilateral neck exploration under local anesthesia: the approach of choice for asymptomatic primary hyperparathyroidism. Surgery $19991261004-1010$.

16 Inabnet WB III, Dakin GF, Haber RS, Rubino F, Diamond EJ \& Gagner M. Targeted parathyroidectomy in the era of intraoperative parathormone monitoring. World Journal of Surgery 2002 $26921-925$.

17 Bergenfelz A, Lindblom P, Tibblin S \& Westerdahl J. Unilateral versus bilateral neck exploration for primary hyperparathyroidism: a prospective randomized controlled trial. Annals of Surgery $2002236543-551$.

18 Gagner M. Endoscopic subtotal parathyroidectomy in patients with primary hyperparathyroidism. British Journal of Surgery 199683875.

19 Henry JF, Iacobone M, Mirallie E, Deveze A \& Pili S. Indications and results of video-assisted parathyroidectomy by a lateral approach in patients with primary hyperparathyroidism. Annals of Thoracic Surgery $1992 \mathbf{5 4} 800-807$.

20 Miccoli P, Berti P, Materazzi G \& Donatini G. Minimally invasive video assisted parathyroidectomy (MIVAP). European Journal of Surgical Oncology 200329 188-190.

21 Lokey J, Mondragon-Sanchez A, Salazar Navarro F, Pattou F, Carnaille B, Huglo D et al. Radioguided surgery for primary 
hyperparathyroidism. Experience in 75 cases. Annales de Chirurgie $2001126535-540$.

22 Rubello D, Casara D, Saladini G, Piotto A, Pagetta C \& Pelizzo MR. 99mTc-MIBI radio-guided surgery in primary hyperparathyroidism: a prospective study of 128 patients. Tumori $2002 \mathbf{8 8}$ S63-S65.

23 Shabtai M, Ben-Haim M, Muntz Y, Vered I, Rosin D, Kuriansky J et al. 140 consecutive cases of minimally invasive, radioguided parathyroidectomy. Surgical Endoscopy $2003 \quad 140$ (In press).

24 Sackett WR, Barraclough B, Reeve TS \& Delbridge LW. Worldwide trends in the surgical treatment of primary hyperparathyroidism in the era of minimally invasive parathyroidectomy. Archives of Surgery 2002137 1055-1059.

25 Norman J \& Denham D. Minimally invasive radioguided parathyroidectomy in the reoperative neck. Surgery $1998 \mathbf{1 2 4}$ 1088-1092.

26 Denham DW \& Norman J. Cost-effectiveness of preoperative sestamibi scan for primary hyperparathyroidism is dependent solely upon the surgeon's choice of operative procedure. Journal of the American College of Surgeons 1998186 293-304.

27 Schell SR \& Dudley NE. Clinical outcomes and fiscal consequences of bilateral neck exploration for primary idiopathic hyperparathyroidism without preoperative radionuclide imaging or minimally invasive techniques. Surgery $200313332-39$.

28 Irvin GL III, Sfakianakis G, Yeung L, Deriso GT, Fishman LM, Molinari AS et al. Ambulatory parathyroidectomy for primary hyperparathyroidism. Archives of Surgery $1996 \mathbf{1 3 1}$ 1074-1078.

29 Udelsman R. 656 consecutive explorations for primary hyperparathyroidism. Annals of Surgery 2002235 665-672.

30 Utiger RD. Treatment of primary hyperparathyroidism (editorial). New England Journal of Medicine 1999341 1301-1302.

31 Clark OH. Mediastinal parathyroid tumors. Archives of Surgery 1988123 1096-1100.

32 Russell CF, Edis AJ, Scholz DA, Sheedy PF \& van Heerden JA. Mediastinal parathyroid tumors: experience with 38 tumors requiring mediastinostomy for removal. Annals of Surgery 1981 $193805-809$.

33 Ipponsugi S, Takamori S, Suga K, Koga T, Hayashi A, Sirouzu K et al. Mediastinal parathyroid adenoma detected by $99 \mathrm{mTc}-\mathrm{meth}$ oxyisobutylisonitrile: report of a case. Japanese Journal of Surgery $19902081-86$.

34 Prinz RA, Lonchyna V, Carnaille B, Wurtz A \& Proye C. Thoracoscopic excision of enlarged mediastinal parathyroid glands. Surgery $1994116999-1004$.

35 Knight R, Ratzer ER, Fenoglio ME \& Moore JT. Thoracoscopic excision of mediastinal parathyroid adenomas: a report of two cases and review of the literature. Journal of the American College of Surgeons $1997 \mathbf{1 8 5} 481-485$.

36 Cupisti K, Dotzenrath C, Simon D, Roher HD \& Goretzki PE. Therapy of suspected intrathoracic parathyroid adenomas. Experiences using open transthoracic approach and video-assisted thoracoscopic surgery. Langenbeck's Archives of Surgery 2002386 488-493.

37 Coakley AJ, Kettle AG, Wells CP, O'Doherty MJ \& Collins RE. 99Tcm sestamibi - a new agent for parathyroid imaging. Nuclear Medicine Communications $198910791-794$.

38 Taillefer R, Boucher Y, Potvin C \& Lambert R. Detection and localization of parathyroid adenomas in patients with hyperparathyroidism using a single radionuclide imaging procedure with technetium-99m-sestamibi. Journal of Nuclear Medicine 199210 1801-1809.

39 Civelek AC, Ozalp E, Donovan P \& Udelsman R. Prospective evaluation of delayed Tc-99m sestamibi SPECT scintigraphy for preoperative localization of primary hyperparathyroidism. Surgery 2002131 149-157.

40 Gaz RD, Doubler PB \& Wang CA. The management of 50 unusual hyperfunctioning parathyroid glands. Surgery 1987102 949-957.
41 Norton JA, Schneider PD \& Brennan MF. Median sternotomy in reoperations for primary hyperparathyroidism. World Journal of Surgery $19859807-813$.

42 Wang C, Gaz RD \& Moncure AC. Mediastinal parathyroid exploration: a clinical and pathologic study of 47 cases. World Journal of Surgery $198610687-695$.

43 Medrano C, Hazelrigg SR, Landreneau RJ, Boley TM, Shawgo T \& Grasch A. Thoracoscopic resection of ectopic parathyroid glands. Annals of Thoracic Surgery 200069 221-223.

44 Dubost C, Bedig G, Gossot D \& Sarfati E. Adenoma of the middle mediastinum clearly visible at scintigraphy. La Presse Médicale $1987 \mathbf{7 6} 176$

45 Proye C, Lefebvre J, Bourdelle-Hego MF, Francois M, Carnaille B, Foucher $\mathrm{C}$ et al. Middle mediastinal parathyroid adenoma of the aorto-pulmonary window. 2 cases. Chirurgie 1988114 166-173.

46 Obara T, Fujimoto Y, Tanaka R, Ito Y, Kodama T, Yashiro T et al. Mid-mediastinal parathyroid lesions: preoperative localization and surgical approach in two cases. Japanese Journal of Surgery 1990 20 481-486.

47 Doppman JL, Skarulis MC, Chen CC, Chang R, Pass HI, Fraker DL et al. Parathyroid adenomas in the aortopulmonary window. Radiology 1996201 456-462.

48 McHenry C, Walsh M, Jarosz H, Henkin R, Tope J, Lawrence AM et al. Resection of parathyroid tumor in the aorticopulmonary window without prior neck exploration. Surgery $1988 \mathbf{1 0 4}$ 1090-1094.

49 Doherty GM, Doppman JL, Miller DL, Gee MS, Marx SJ, Spiegel AM et al. Results of multidisciplinary strategy for management of mediastinal parathyroid adenoma as a cause of persistent primary hyperparathyroidism. Annals of Surgery $1992 \mathbf{2 1 5}$ 101-106.

50 Heller HJ, Miller GL, Erdman WA, Snyder WH III \& Breslau NA. Angiographic ablation of mediastinal parathyroid adenomas: local experience and review of the literature. American Journal of Medicine 199497 529-534.

51 Wei JP, Gadacz TR, Weisner LF \& Burke GJ. The subxiphoid laparoscopic approach for resection of mediastinal parathyroid adenoma after successful localization with Tc-99m-sestamibi radionuclide scan. Surgical Laparoscopy and Endoscopy $1995 \mathbf{5}$ 402-406.

52 Kido T, Hazama K, Inoue Y, Tanaka Y \& Takao T. Resection of anterior mediastinal masses through an infrasternal approach. Annals of Thoracic Surgery 199967 263-265.

53 Landreneau RJ, Mack MJ, Hazelrigg SR, Dowling RD, Acuff TE Magee MJ et al. Video-assisted thoracic surgery: basic technical concepts and intercostal approach strategies. Annals of Thoracic Surgery $1992 \mathbf{5 4} 800-807$.

54 Smythe WR, Bavaria JE, Hall RA, Kline GM \& Kaiser LR. Thoracoscopic removal of mediastinal parathyroid adenoma. Annals of Thoracic Surgery $199559236-238$.

55 O'Herrin JK, Weigel T, Wilson M \& Chen H. Radioguided parathyroidectomy via VATS combined with intraoperative parathyroid hormone testing: the surgical approach of choice for patients with mediastinal parathyroid adenomas? Journal of Bone and Mineral Research $2002171368-1371$.

56 Furrer M, Leutenegger AF \& Ruedi T. Thoracoscopic resection of an ectopic giant parathyroid adenoma: indication, technique, and three years follow-up. Thoracic and Cardiovascular Surgery $199644208-209$.

57 Yoshida T, Nagahama T, Maruyama M \& Ebuchi M. Thoracoscopically managed parathyroid adenoma in the upper anterior mediastinum. Surgical Laparoscopy, Endoscopy and Percutaneous Techniques 2001 11 385-388.

58 Di Bisceglie M, Voltolini L, Paladini P, Cacchiarelli M, Vella A \& Gotti G. Ectopic parathyroid adenoma. Two cases treated with video-assisted thoracoscopic surgery. Scandinavian Cardiovascular Journal $19983251-52$.

59 Peix JL, Van Box Som P, Claeys K \& Lapras V. Excision of a parathyroid adenoma of the aorto-pulmonary window under thoracoscopy. La Presse Médicale 199625 494-496. 
60 Ott MC, Malthaner RA \& Reid R. Intraoperative radioguided thoracoscopic removal of ectopic parathyroid adenoma. Annals of Thoracic Surgery 200172 1758-1760.

61 Gullstrand P, Olsson G, Olsson M, Sundkvist K, Leidner B \& Martensson O. Thoracoscopic parathyroidectomy of an ectopic adenoma. British Journal of Surgery $1996 \mathbf{8 3} 1757$.

62 Lesser T \& Bartel M. Videothoracoscopic excision of mediastinal parathyroid adenoma. European Journal of Surgery 1999165 395-397.

63 Norman JG, Jaffray CE \& Chheda H. The false-positive parathyroid sestamibi: a real or perceived problem and a case for radioguided parathyroidectomy. Annals of Surgery 2000231 31-37.

64 Kim CK, Jung E, Yun M, Lorberboym M, Mechanick JI, Bergman D et al. A normal variant on Tl-201 and Tc-99m MIBI whole-body imaging: the superior right atrial wall (auricle) and superoanterior right ventricular wall are often seen as mediastinal lesions. Clinical Nuclear Medicine 200126 412-418.

65 Granato MP, Rodriguez MS, Elshazly SM, Barron BJ \& Lamki L. Potential pitfall in parathyroid sestamibi imaging resulting from a cardiac pacemaker. Clinical Nuclear Medicine 200126 74-75.

66 Nilsson BE, Tisell LE, Jansson S, Zackrisson BF, Lindstedt G \& Lundberg PA. Parathyroid localization by catheterization of large cervical and mediastinal veins to determine serum concentrations of intact parathyroid hormone. World Journal of Surgery $199418605-610$.

67 Even-Sapir E, Keidar Z, Sachs J, Engel A, Bettman L, Gaitini D et al. The new technology of combined transmission and emission tomography in evaluation of endocrine neoplasms. Journal of Nuclear Medicine 2001 42 998-1004.

68 Rubello D, Casara D, Fiore D, Muzzio P, Zonzin G \& Shapiro B. An ectopic mediastinal parathyroid adenoma accurately located by a single-day imaging protocol of Tc-99m pertechnetate-MIBI subtraction scintigraphy and MIBI-SPECT-computed tomographic image fusion. Clinical Nuclear Medicine 200227 186-190.

69 Sofferman RA \& Nathan MH. The ectopic parathyroid adenoma: a cost justification for routine preoperative localization with technetium Tc $99 \mathrm{~m}$ sestamibi scan. Archives of Otolaryngology - Head and Neck Surgery 1998124 649-654.

Received 15 July 2003

Accepted 11 November 2003 